\title{
Brief Study about the Function of Intercultural Nonverbal Communication in English Language Teaching
}

\author{
Lan Zheng \\ Xi'an Peihua University, Xi'an, Shanxi, China, 710100 \\ Email:747481089@qq.com
}

\begin{abstract}
Study of nonverbal communication has already caught much attention in the intercultural communication academic and English language teaching filed. Nonverbal communication has been neglected for a long time in the traditional English teaching in china. Nonverbal communication is the indispensable component in the process of communication, it has strong cultural trait. Neglect of nonverbal communication and cultural differences of nonverbal communication behavior, only paying attention to language communication is not a kind of complete and successful teaching. Therefore, nonverbal communication is an integral part of English language teaching, in order to improve the students' ability of communication and using language, train qualified talents of English language, beginning with talking about the significance of intercultural nonverbal communication in English language teaching, this paper will analysis the function of nonverbal communication in foreign language teaching.
\end{abstract}

Keywords: Intercultural Nonverbal Communication, English Language Teaching, Function.

\section{Introduction}

There are two kinds of channels in human communication: verbal communication and non-verbal communication. Nonverbal communication refers to all the communicative behaviors except to language performance. In modern English teaching, the mode of foreign language teaching is no longer like traditional class mode, which is teachers are not the saints on the platform, students are not passive learner, it is a brand-new flipped classroom, which is learner-centered instruction and teacher-directed new mode, English teaching not only should pay attention to the knowledge transfer, but also the combination between in the class and outside class and construction of verbal and non-verbal. Constantly seeking available teaching mode, which can make teachers are able to present and transfer knowledge clearly and flexibly, and students' are capable of understanding and absorbing knowledge easily and solidly, is a hot topic that was discussed and pursuit by plenty of scholars and scientists. Word of mouth simply and lecture-style teaching methods have been unable to meet demand present, it is inevitable that we should combine non-verbal communication behavior with traditional linguistic teaching mode. Actually, in the classroom teaching, teaching is not only instill the knowledge into the students but exchange with each other. Although language expression exchange is very important and basal, nonverbal communication has a significant impact on English classroom teaching. In addition, nonverbal communication ability can help teacher manage class effectively, cover the shortage of language communication, and enhance the character and charm of language, it also can inspire students' learning motivation, strengthen students' learning interest, thereby improving students' learning efficiency. Therefore, how to consciously apply non-verbal communication in college English teaching, and maximum display its positive role, trying to avoid and reduce negative influence of nonverbal communication in English teaching, is a pressing matter of the moment. Only combination of the language and nonverbal communication can make our English classroom more actively and effectively.

\section{Non-verbal Communication}

\subsection{Definition of Non-verbal Communication}

As to nonverbal communication, there are many different definitions, some definitions are very simple, for example: nonverbal communication is communication without words; Burgon and Saine 
gave their definition about nonverbal communication in 1978, nonverbal communication as those actions and attributes of humans that have socially shared meaning, are intentionally sent or interpreted as intentional, are consciously sent or consciously received, and have the potential for feedback from the receiver, which means that it refers to sort of attributes or behaviors of human being, those attributes and behaviors were send consciously and unconsciously by sender. In a sense, nonverbal communication is a process in which communicators use the natural features of their bodies to deliver information and express specific meaning instinctively to the other communicators. It is a kind of communication through sending and receiving wordless signals. Narrowly speaking, nonverbal communication also refers to intentional use of non-spoken symbol to communicate a specific message.

\subsection{Expression Forms of Non-verbal Communication}

According to the functions of nonverbal communication: replacing spoken messages; sending uncomfortable messages; forming impressions that guide communication; making relationship clear; regulating interaction; reinforcing and modifying verbal messages, expression forms of non-verbal communication, non-verbal communication includes three kinds of expression forms.

Firstly, body language. Body language refers to all nonverbal symbols that are associated with body behaviors. It studies the meaning of body movement when human communicate with others. Body language includes many kinds of nonverbal behaviors, such as general appearance and dress, gestures, eye contact, facial expression, posture touching and other displays that can be used to communicate, and gesture is the hard-core of body language. Those emblem, culture-specific and conventional gestures can be used as replacement for language. A single quotable gesture can express different meaning under different cultural contexts. So, teachers should appropriate expression and friendly smile in classroom teaching, which can reduce the distance between teachers and students. Eye contact can decrease dispersion of attention. Body language can reflect teachers' mental state and sprite, its appropriate use can create harmonious and high-efficiency classroom.

Secondly, paralanguage. Paralanguage refers to voice characteristics and vocal qualities. It studies non-semantic aspects of speech, such as tone, volume, pitch and silence, which can send us some information superior to language characters. Through paralanguage, human can judge tone, status, attitude and content authenticity of the speakers. Different paralanguages of the teachers can transmit different potential information to students, students give response with different paralanguage. Meanwhile, to learner, the efficiency of learning not only depends on the content of teaching, but also has much to do with teaching methods, in English teaching class; the effective information transmission can make the information show more clearly and vividly. Loud sound, high tone and a faster speed are more likely to attract students' attention than plain sound, low tone and slower speed. A moment's silence and a long pause would have comparative and emphasis effect on language teachers speak, and also can control the noise of the classroom. Students will keep silence when they cannot understand the content of class and answer questions, or they disagree with the teacher's opinion and think about the question.

Thirdly, environmental language mainly includes space information and time information. As to English class, environmental factors embodied in phenomena of classroom communication and internal and external environment of communication, for example, school buildings' design, appearance and color of classroom, light and lighting conditions, seat arrangement, communicate attitudes, feelings and relationships on both side and so on. Those environment factors can influence the acceptance of information and behaviors of communicators directly and indirectly. A comfort, ease and warm surrounding will let speakers transfer information correctly, and let receivers accept and absorb knowledge information actively and effectively.

\section{Function of Non-verbal Communication in English Class}

Human communication is divided into verbal communication and non-verbal communication; non-verbal communication plays an important role in English teaching as a supplementary means. Teachers' non-verbal communication behaviors embodied in body language, paralanguage, object 
language and environmental language. Teachers' non-verbal communication plays an necessary role in promoting students' enthusiasm, improving the teaching efficiency, creating harmonious class atmosphere and enhancing class management. In English classroom teaching, the teacher should reasonably, effectively and timely utilize interpersonal distance, eye contact, facial expressions, paralanguage, posture, object language and environmental language to facilitate the English classroom teaching.

\subsection{Nonverbal Communication can Build Good Relationship between Teachers and Students}

Nonverbal communication can build good relationship between teachers and students, and create a harmonious atmosphere in English class teaching. Teachers are amiable and approachable in class, role differences between teachers and students will reduce, and psychological pressure of students will decrease. Thereby harmonious teaching atmosphere can build easily. When students meet some questions, if teacher help students solve them with a smile on her or his face, students would like to seek the help from teachers and communicate with them, so, the relationship between teachers and students becomes more and more close, students' learning interest will improve, in contrast, indifferent and solemn expression lead to the inner sense of distance, students is scared of teachers, they would like to hide their problems, as time passes, students' learning problems will mount, the relationship between teacher and students become more and more serious, the space and gap between them will become more and more big. Teacher assumes responsibility for imparting knowledge and educating talent, in teaching, teacher should improve ideological work through reason and empathy; in educating talent, teacher should kindness, intimacy and taking care of students, students' non-intelligence factors would grow up healthily, the relationship between teachers and students will be very harmonious.

\subsection{Nonverbal Communication can Make Classroom Management more Recessive and Efficiency}

Recessive management refers to that teachers influence students' behavior and psychology through non-verbal communication means. Teachers' mild look, signal nod, satisfied smile and approval gestures show that they are satisfied with the students' reflection; in contrast, disapproval eyes, tight frown, harsh tone and helpless shaking head and suspiration expressed disagreement of students' behaviors. When students talk with each other or do something unrelated with the teaching content in classroom, teacher should give them serious expression and look, and then slow down the pace of speech or stop for a few seconds; when students are in the state of being drowsy or inattentive, teacher can clap their shoulders in the case of disturbing other students; teacher should praise students' merits to reduce the incidence of bad behavior; those can play role in controlling and regulating function to students' behaviors what was happening, actually, it is more effective than verbal behavior.

\subsection{Nonverbal Communication can Encourage Students, Arouse Their Learning Interest and Enthusiasm}

Human visual and auditory attention will feel tired and fatigue concentrated in one place for a long time. Teachers' understanding smile, hostile glance, appropriate intonation, clean and decent instrument, timely gesture and appropriate spatial distance let students change the central point, their learning interest will be very strong, and such non-verbal communication used in class can increase students' ability to block out distractions. Visual aid and vivid illustrations can arouse their learning interest. The teaching mode combined with non-verbal communication will be able to take away inherent and mechanical traditional English teaching mode; students' learning activity and enthusiasm will be increased.

\subsection{Nonverbal Communication can Make the Teaching more Lively, Strengthen Teaching Effect}

Teachers' eye contact, facial expressions, posture and tone will make English classroom teaching vividly, effective of teaching will be better than single language communication. Study shows that much of the effect of classroom realize through utilizing of non-verbal communication of teachers in class. Teacher, as the transmitter of knowledge and language communicator, should 
use non-verbal communication appropriately in class, which can make English class more colorful and appealing, thereby teaching become more vividly; teaching effect become more remarkable.

\section{How to Use Non-verbal Communication Effectively in English Class Teaching}

Rose thought that the result of study proves that information transferred by language communication occupies 35\%; but nonverbal communication occupies $65 \%$ high in human communication. $82 \%$ of the teaching effects come true through teacher's facial expression and behaviors in English teaching class, only $18 \%$ information achieved through language communication. Therefore, how to use non-verbal communication effectively in English class teaching seems very significant. Utilization of teachers' non-verbal communication should pay attention to teaching skills, maintain an appropriate degree of interpersonal space, use eye contact freely, use facial expression, posture and gesture appropriately, and in class teaching, teacher should also pay attention to communicate with students with paralanguage slickly and transfer teaching information effectively, use object language to create harmonious teacher-student relationship; and use environment language appropriately to build good teaching and learning environment; and attach important to non-verbal feedback of students; last but not least, teacher should improve non-verbal communicative competence themselves.

\section{Conclusions}

At present, non-verbal communication's development in china is still in infancy; most teachers in college haven't systematic and in-depth understanding and command about non-verbal communication knowledge. The organic combination of non-verbal communication and English teaching, and systematic application of it into English teaching class is still a new idea, this new mode of ideation can not only close the relationship between teacher and student, break traditional English teaching mode, but also enhance student's learning interest and teacher's teaching efficiency and quality, thereby make a true combination of language and culture; while passing on teaching knowledge, English education in college should also pay more attention to transmit English countries' culture. Therefore, applying non-verbal communication in English teaching will bring change and development of English classroom teaching.

\section{References}

[1] Andersen.Peter. Nonverbal Communication: Forms and Functions (2nd ed.). Waveland Press. 2007.

[2] Liu Shuai, Study of Application of Non-verbal Communication in College English Class. Education Teaching Forum, No: 23. 2016.

[3] Hanna, Judith L. To Dance Is Human: A Theory of Nonverbal Communication. Chicago: University of Chicago Press. 1987.

[4] Pease B.; Pease A. The Definitive Book of Body Language. New York, NY: Bantam Books.2004.

[5] Information on http://www.lwlm.com.

[6] Driver, J. You Say More Than You Think. New York, NY: Crown Publishers. 2010.

[7] Paradise, Ruth. "Interactional Style and Nonverbal Meaning: Mazahua Children Learning How to Be Separate-But-Together". Anthropology \& Education Quarterly. 25 (2): 156-172. 1994.

[8] Zhou Peiyun, The Application of Non-verbal Communication in English Class. Journal of Qiqiha'r College, No:151.2016. 